\title{
Mixed total anomalous pulmonary venous connection: Anatomic variations, surgical approach, techniques, and results
}

Ujjwal K. Chowdhury, MCh, Diplomate NB, ${ }^{a}$ Balram Airan, MCh, ${ }^{a}$ Amber Malhotra, MS, ${ }^{a}$ Akshay K. Bisoi, MCh, ${ }^{a}$ Anita Saxena, DM, ${ }^{\mathrm{b}}$ Shyam S. Kothari, DM, FACC, ${ }^{\mathrm{b}}$ Mani Kalaivani, MSc. (Biostatistics), ${ }^{\mathrm{c}}$ and Panangipalli Venugopal, $\mathrm{MCh}^{\mathrm{a}}$

Supplemental material is available online.
From the Departments of Cardiothoracic Surgery, ${ }^{\mathrm{a}}$ Cardiology, ${ }^{\mathrm{b}}$ and Biostatistics, ${ }^{\mathrm{c}}$ All India Institute of Medical Sciences, New Delhi, India.

Received for publication April 21, 2007; revisions received Aug 23, 2007; accepted for publication Aug 30, 2007.

Address for reprints: Ujjwal K. Chowdhury, $\mathrm{MCh}$, Additional Professor, Department of Cardiothoracic and Vascular Surgery, All India Institute of Medical Sciences, New Delhi110029, India (E-mail: ujjwalchow@ rediffmail.com; ujjwalchowdhury@gmail. com).

J Thorac Cardiovasc Surg 2008;135:106-16 $0022-5223 / \$ 34.00$

Copyright (๑) 2008 by The American Association for Thoracic Surgery

doi:10.1016/j.jtcvs.2007.08.028
Objective: The purpose of this study was to identify the morphologic characteristics and other risk factors that may predispose patients with mixed totally anomalous pulmonary venous connection to continuing high mortality after surgery.

Methods: Fifty-seven consecutive patients aged 15 days to 18 years (median, 6 months) underwent rechanneling of mixed totally anomalous pulmonary venous connection. Twenty-three patients had " $2+2$ " pattern (I category), 29 had " $3+1$ " pattern (II category), and 5 patients had pulmonary venous connections of different combinations (III category). Obstructive patterns involving one or more pulmonary veins were present in $19(33.3 \%)$ patients.

Results: Operative and late mortality rates were $19.3 \%$ and $4.3 \%$, respectively. At a mean follow-up of $63.26 \pm 58.47$ months, actuarial survival was $86.9 \% \pm 0.07 \%$ in category I, $86.2 \% \pm 0.06 \%$ in category II, and $20.0 \% \pm 0.18 \%$ in category III (log-rank, $P=.001)$, respectively. At their last follow-up, all survivors $(\mathrm{n}=43)$ had a Ross clinical heart failure score of 0 to 2 .

Conclusions: Patients with a " $2+2$ " pattern of mixed totally anomalous pulmonary venous connection constitute the safe anatomic category for rechanneling, followed by the " $3+1$ " variety. Cross-sectional echocardiography and/or computed tomographic angiography are mandatory to provide necessary diagnostic information and define the anatomy. Patients aged 2 months or younger, obstructive totally anomalous pulmonary venous connection, and perioperative pulmonary hypertensive crises were significant risk factors for death by logistic regression analysis. The risk of death was 5.85 times higher (95\% confidence interval: $1.46-35.68 ; P=.02$ ) in patients with category III of mixed TAPVC. The precise technique adopted in an individual patient depends on the pattern of anatomic drainage, and an individualized surgical approach is recommended.

$\mathrm{D}$ espite steady improvement in surgical outcomes of total anomalous pulmonary venous connection (TAPVC) over time, the management strategy and results of surgery of the mixed variety of TAPVC are limited and conflicting. ${ }^{1-6}$ Although the morphologic heterogeneity of the venous connections, incomplete ascertainment of the anatomy, length of the confluent chamber, presence or absence of obstruction, and surgical treatment modalities have been variously implicated as the causative factors for continuing high mortality, there is as yet an insufficient appreciation of the entire spectrum of mixed TAPVC. ${ }^{1-6}$ The objectives of this study were as follows: (1) to identify the morphologic characteristics, (2) to evaluate the early and long-term results of rechanneling of mixed TAPVC, (3) to identify the risk factors for continuing high mortality after surgery, and (4) to provide certain guidelines for an individualized surgical approach. 


\author{
Abbreviations and Acronyms \\ ASD = atrial septal defect \\ $\mathrm{CI}=$ confidence interval \\ $\mathrm{CPB}=$ cardiopulmonary bypass \\ $\mathrm{CT}=$ computed tomography \\ PAP $=$ pulmonary artery pressure \\ RA = right atrium \\ $\mathrm{SD}=$ standard deviation \\ SVC = superior vena cava \\ TAPVC $=$ total anomalous pulmonary venous \\ connection
}

\section{Patients and Methods}

Between January 1991 and December 2006, 514 patients underwent rechanneling of TAPVC at AIIMS, New Delhi, India. Of these, $57(11.1 \%)$ consecutive patients (36 male) with a mixed variety of TAPVC, either isolated or associated with visceral heterotaxy, underwent surgical repair and were included in this retrospective study. For the retrospective review and collation of the data, "Ethics Committee Approval of Human Subject Health Record and Research" was obtained from the research ethical board in the hospital.

The records of these patients were reviewed for demographic, clinical, preoperative, operative, postoperative, and follow-up data (Table E1). Age at operation ranged from 15 days to 18 years (mean $\pm \mathrm{SD}, 18.40 \pm 40.12$ months; median, 6 months). Twelve (21\%) patients were less than 2 months of age and $14(24.5 \%)$ patients were more than 12 months of age. Weight at surgical repair ranged from 2.5 to $46 \mathrm{~kg}$ (mean $\pm \mathrm{SD}, 5.12 \pm 5.85 \mathrm{~kg}$; median, $5 \mathrm{~kg}$ ). Most patients in this study group were small for age and $43.8 \%(n=25)$ weighed less than the 50th percentile of predicted weight for Indian neonates and infants. Radiographic studies showed asymmetric pulmonary venous congestion involving either the left or right side in 15 (26.3\%) patients.

Preoperative diagnostic studies included both echocardiography and cardiac catheterization in 29 patients. Cross-sectional echocardiography (HP Sonos 5500; Hewlett-Packard Company, Andover, Mass) was the only diagnostic study in 21 patients, and computed tomographic (CT) angiography (Siemens Somatom Sensation 16; Siemens AG, Berlin, Germany) was required for visualization of the pulmonary venous anatomy in 7 patients. Cardiac catheterization was performed if echocardiography could not adequately define the anatomy and to measure pulmonary artery pressure (PAP) in late presenters. Balloon atrial septostomy was done in only $2(3.5 \%)$ patients. For patients who underwent preoperative cardiac catheterization (n $=29$ ), systolic PAP ranged from 38 to $83 \mathrm{~mm} \mathrm{Hg}$ (mean $\pm \mathrm{SD}$, $58.80 \pm 12.52 \mathrm{~mm} \mathrm{Hg}$ ). The ratio of systolic PAP to systemic systolic arterial pressure ranged from 0.5 to 1.2 (mean $\pm \mathrm{SD}$, $0.72 \pm 0.18)$. Preoperative oxygen saturation ranged from $70 \%$ to $94 \%$ (mean, $75 \% \pm 4 \%$ ). Four $(7.0 \%$ ) patients required emergency operation for hemodynamic compromise and required ventilatory and inotropic support.

We used the descriptions of echocardiographic, angiographic, and surgical findings of 57 patients to stratify the various cases and allocated them into different groups as proposed in our earlier publication (Tables 1 to 3$).^{7}$ For data analysis and uniformity with other studies, the patients were allocated into three categories.

Category I: Bilateral and symmetrical connections. This group of patients had separate anomalous connection of veins from each lung: " $2+2$ " pulmonary venous drainage pattern $(\mathrm{n}=23$; Table 1; Figure 1, $A$ to $D$ ).

TABLE 1. Group of patients with separate anomalous connection of veins from each lung (veins from each lung joined a homolateral confluence and drained into the systemic veins at separate sites: " $2+2$ " pattern of drainage)

Sites of drainage

RSPV and RIPV to coronary sinus; LSPV and LIPV to brachiocephalic vein via vertical vein (Figure 1, A)

RSPV and RIPV to SVC-RA junction; LSPV and LIPV to brachiocephalic vein via vertical vein (Figure 1, B)

RSPV and RIPV to SVC-RA junction; LSPV and LIPV to RA (Figure 1, C)

Pulmonary veins from right and left lungs joined a respective pulmonary venous confluence. From each confluence, two separate vertical veins descended into the abdomen; the vein from the right lung joined the ductus venous, and the vein from the left joined the portal vein (Figure 1, D) rechanneled to $L A$; vertical vein transected and anastomosed to $L A A$; Dacron patch partition between CPVC and RA

Combination of Serraf modified superior approach ${ }^{10}$ and classic Warden technique ${ }^{11}$ for sinus venosus repair

Combination of classic Warden ${ }^{11}$ technique for sinus venosus repair and Dacron patch partition between pulmonary veins and $\mathrm{RA}^{10}$

Right and left venous confluence anastomosis; CPVC to LA anastomosis; ligation of the descending vertical vein (Kanjuh technique ${ }^{12}$ )

$C P V C$, Common pulmonary venous connection; $L A$, left atrium; $L A A$, left atrial appendage; $L I P V$, left inferior pulmonary vein; $L S P V$, left superior pulmonary vein; $R A$, right atrium; $R I P V$, right inferior pulmonary vein; $R S P V$, right superior pulmonary vein; $S V C$, superior vena cava. 
TABLE 2. Group of patients with isolated drainage of a solitary pulmonary vein at different body levels and drainage of the other three pulmonary veins to a common site (" $3+1 "$ pattern of drainage)

\begin{tabular}{|c|c|c|}
\hline Sites of drainage & Operations performed & cases \\
\hline $\begin{array}{l}\text { LSPV to brachiocephalic vein via vertical vein; LIPV, RSPV, } \\
\text { and RIPV to coronary sinus (Figure } 2, A \text { ) }\end{array}$ & $\begin{array}{l}\text { Unroofing of coronary sinus; patch closure, ASD } \\
\text { (Van Praagh or Mee technique) }\end{array}$ & 20 \\
\hline $\begin{array}{l}\text { LSPV to brachiocephalic vein via vertical vein; LIPV, RSPV } \\
\text { and RIPV joined to form common chamber and drained } \\
\text { infradiaphragmatically (Figure } 2, B \text { ) }\end{array}$ & $\begin{array}{l}\text { Apex of heart elevated over to right pleural cavity; } \\
\text { CPVC-LA anastomosis using a contiguous } \\
\text { portion of vertical vein (posterior approach). }\end{array}$ & 5 \\
\hline $\begin{array}{l}\text { RSPV, RMPV to SVC-RA junction; RIPV, LSPV, and LIPV to } \\
\text { brachiocephalic vein via vertical vein (Figure } 2, C \text { ) }\end{array}$ & Rechanneling by Berdat technique ${ }^{13}$ & 1 \\
\hline $\begin{array}{l}\text { RSPV to high right SVC; RIPV, LSPV, and LIPV draining } \\
\text { directly into RA (Figure } 2, D \text { ) }\end{array}$ & Rechanneling by van Son technique ${ }^{14}$ & 1 \\
\hline $\begin{array}{l}\text { RSPV to coronary sinus; RIPV, LSPV, and LIPV joined to } \\
\text { form a common chamber and drained in brachiocephalic } \\
\text { vein (Figure } 2, E \text { ) }\end{array}$ & $\begin{array}{l}\text { CPVC-LA anastomosis (posterior approach); RSPV } \\
\text { rechanneled into RA by unroofing of the } \\
\text { coronary sinus }\end{array}$ & 1 \\
\hline $\begin{array}{l}\text { LSPV to vertical vein with dual drainage to brachiocephalic } \\
\text { vein and coronary sinus; LIPV, RSPV, and RIPV joined to } \\
\text { form a common chamber to drain in coronary sinus } \\
\text { (Figure } 2, \mathrm{~F} \text { ) }\end{array}$ & $\begin{array}{l}\text { Vertical vein-brachiocephalic vein junction, ligated; } \\
\text { coronary sinus unroofed; all pulmonary veins } \\
\text { rechanneled into LA; Dacron patch partition } \\
\text { between CPVC and RA }\end{array}$ & 1 \\
\hline Total & & 29 \\
\hline
\end{tabular}

$A S D$, Atrial septal defect; $C P V C$, common pulmonary venous connection; $L A$, left atrium; $L I P V$, left inferior pulmonary vein; $L S P V$, left superior pulmonary vein; $R A$, right atrium; $R I P V$, right inferior pulmonary vein; $R S P V$, right superior pulmonary vein; $S V C$, superior vena cava.

Category II: Bilateral and asymmetrical connections.

This group of patients had isolated drainage of a solitary pulmonary vein and drainage of the other three pulmonary veins to a common site: "3+1" pulmonary venous drainage pattern $(\mathrm{n}=29$; Table 2; Figure 2, $A$ to $F$ ).

Category III: Bizarre anatomic variants. This group of patients had bizarre anatomic variants $(n=5$; Table 3 ; Figure 3, $A$ to $E$ ).

The obstructive pattern of TAPVC involving one or more pulmonary veins was present in $19(33.3 \%)$ patients. The sites of obstruction were at the vertical vein-brachiocephalic vein junction in 5 patients, at the superior vena cava-right atrial (SVC-RA) junction in 2 patients, at the common chamber and coronary sinus junction in 3 patients, at the vertical vein-portal vein junction in 4 patients, at the vertical vein-ductus venosus junction in 1 patient, at the interatrial communication in 3 patients, and at a retrocardiac plexus of veins in 1 patient. One $(1.7 \%)$ patient had a functionally univentricular heart with visceral heterotaxy. RA isomerism was present in $7(12.3 \%)$ patients. The ductus arteriosus was patent in $26(45.6 \%)$ patients.

\section{Definitions}

TAPVR was considered to be of mixed variety on the basis of the pulmonary venous drainage pattern to the systemic venous system at multiple levels without a pulmonary venous confluence, which is potentially a combination of the following:

- Supracardiac (left cardinal vein, SVC-RA junction)

- Infracardiac to the portal vein and ductus venosus

- Cardiac to the coronary sinus

- Scimitar or "aberrant" in the inferior vena cava or hepatic vein (seen in heterotaxy)
- Mixed TAPVR has not been defined on the basis of the anatomy of the common pulmonary venous trunk (CTSnet Web site).

We considered the mixed form of TAPVR to be isolated or simple if the patient had the anomalous pulmonary venous connections in association with a secundum atrial septal defect (ASD), a patent ductus arteriosus, or both. Patients were considered to have univentricular or biventricular physiology according to whether their anatomy was deemed suitable for univentricular or biventricular repair. Heterotaxy syndrome was defined as complex anomalies of visceral-cardiac relations in association with intracardiac disease.

Preoperatively, pulmonary venous drainage was considered obstructive if there was echocardiographic or angiographic data that indicated (1) a significant gradient between the pulmonary veins and their point of drainage (flow acceleration $>2 \mathrm{~m} / \mathrm{s}$ by echocardiography or a pressure gradient $>4 \mathrm{~mm} \mathrm{Hg}$ ), (2) monophasic and continuous Doppler flow pattern in the individual pulmonary veins, the pulmonary venous confluence, or the vertical vein, or (3) angiographic evidence of localized reduction in a single pulmonary vein diameter of $50 \%$ of more. ${ }^{1-8}$

On the basis of systolic PAP as measured by preoperative cardiac catheterization or on echocardiography on the basis of the velocity of tricuspid regurgitation, pulmonary hypertension was defined as a right ventricular/left ventricular systolic pressure ratio equal to 0.6 An operation was classified as being performed on an emergency basis if the patient was taken to the operating room within the first 24 hours after coming to the hospital for hemodynamic or ventilatory compromise.

To evaluate the functional cardiac status, we assessed these patients according to the Ross heart failure score. This score 
TABLE 3. Group of patients with bizarre anatomic variants of mixed TAPVC

\begin{tabular}{|c|c|c|}
\hline Sites of drainage & Operations performed & $\begin{array}{l}\text { No. of } \\
\text { cases }\end{array}$ \\
\hline $\begin{array}{l}\text { RIPV, LSPV, and LIPV formed a common chamber. The } \\
\text { common chamber drained into SVC-RA junction via } \\
\text { a right middle and right superior pulmonary vein } \\
\text { (Figure } 3, A \text { ) }\end{array}$ & $\begin{array}{l}\text { CPVC-LA anastomosis; ridge between RSPV and ASD, } \\
\text { resected; Dacron patch partition to close the ASD } \\
\text { and baffling of RSPV }\end{array}$ & 1 \\
\hline $\begin{array}{l}\text { RSPV and RIPV joined to form a common vein and } \\
\text { drained into RA. LIPV drained into RA. LSPV drained } \\
\text { via a vertical vein into brachiocephalic vein } \\
\text { (Figure } 3, B \text { ) }\end{array}$ & $\begin{array}{l}\text { Under circulatory arrest, RSPV-RIPV junction } \\
\text { transected and anastomosed to LA; fenestrated } \\
\text { Dacron patch partition redirecting LIPV; vertical } \\
\text { vein-brachiocephalic vein junction transected; LSVC } \\
\text { anastomosed to LAA }\end{array}$ & 1 \\
\hline $\begin{array}{l}\text { RIPV and LIPV joined to form a common chamber and } \\
\text { drained into coronary sinus. RSPV drained separately } \\
\text { into RA. LSPV drained via a vertical vein into left } \\
\text { brachiocephalic vein (Figure } 3, C \text { ) }\end{array}$ & $\begin{array}{l}\text { Coronary sinus unroofed; RSPV, RIPV, LIPV } \\
\text { rechanneled into LA with a PTFE patch; vertical } \\
\text { vein-brachiocephalic vein junction transected and } \\
\text { anastomosed to LAA }\end{array}$ & 1 \\
\hline $\begin{array}{l}\text { RSPV and RIPV drained individually to the coronary sinus } \\
\text { and then to the RA through an obstructed orifice; LSPV } \\
\text { and LIPV formed a common chamber and had dual } \\
\text { drainage to coronary sinus and brachiocephalic vein } \\
\text { via vertical vein (Figure } 3, D \text { ) }\end{array}$ & $\begin{array}{l}\text { Rechanneling of RSPV, RIPV into LA by coronary } \\
\text { sinus unroofing and Van Praagh technique; left- } \\
\text { sided pulmonary veins rechanneled to LAA; vertical } \\
\text { vein connection, left unligated }\end{array}$ & 1 \\
\hline $\begin{array}{l}\text { RSPV and RIPV joined to form a right common pulmonary } \\
\text { vein. LSPV and LIPV joined to form a left common } \\
\text { pulmonary vein. Veins from both lungs drained into a } \\
\text { retrocardiac venous plexus and drained } \\
\text { infradiaphragmatically (Figure } 3, E \text { ) }\end{array}$ & $\begin{array}{l}\text { Under circulatory arrest, posterior pericardium was } \\
\text { opened up. No sizeable venous chamber could be } \\
\text { identified for rechanneling. }\end{array}$ & 1 \\
\hline Total & & 5 \\
\hline
\end{tabular}
superior vena cava.

included the amount of formula consumed per feeding, feeding time, history of diaphoresis or tachypnea, growth parameters, respiratory and heart rates, respiratory pattern, perfusion, presence of edema, diastolic filling sounds, and hepatomegaly. ${ }^{9}$ Using these measurements, we generated a score and converted it into the following categories:

1. 0 to 3 risk points $=$ nil congestive heart failure

2. 3 to 6 risk points $=$ mild congestive heart failure

3. 7 to 9 risk points $=$ moderate congestive heart failure

4. 10 to 12 risk points $=$ severe congestive heart failure

\section{Operative and Postoperative Management}

The surgical techniques and the intraoperative and postoperative management protocols were uniform during the study period. Moderate hypothermic cardiopulmonary bypass (CPB) with aortabicaval cannulation was used in $54(94.7 \%)$ patients. Deep hypothermic circulatory arrest was used in $3(5.3 \%)$ patients. Cold hyperkalemic blood cardioplegia and topical hypothermia were used for myocardial protection in all patients.

Both conventional (on-pump) and immediately post-CPB ultrafiltration (off-pump) was used in patients weighing less than 10 $\mathrm{kg}$ and patients with moderate-to-severe pulmonary arterial hypertension to reduce the total body water and to remove inflammatory mediators from the circulation.

The anatomic variations and frequency of the entire spectrum of cases have been tabulated in Tables 1 to 3 and Figures 1 to 3 .

\section{Surgical Procedures for Various Anatomic Types and Subtypes}

Category I: Bilateral and symmetrical connections. In this group, there were separate anomalous connections of all the veins from each lung, with the veins of each side joining to form confluences that then connected with the systemic veins at separate sites. Thus, the pattern produced a discontinuity of the right-sided and left-sided drainage. Within this group, we identified four different anatomic combinations among 23 (40.3\%) patients. These patients have been conceptually approached as having bilateral partial anomalous pulmonary venous drainage. The details of the morphologic types and operative procedures are summarized in Table 1 and Figure 1, $A$ to $D$.

Category II: Bilateral but asymmetrical connections. In this group, there was isolated drainage of a solitary pulmonary vein from one lung at different levels, with drainage of the other three pulmonary veins to a common site via a confluence. We found six different combinations in a total of $29(50.9 \%)$ patients. The techniques used for rechanneling of various types of " $3+1$ " variety of mixed TAPVC are summarized in Table 2 and Figure 2, $A$ to $F$.

In this variety, the isolated pulmonary vein draining via the vertical vein into the brachiocephalic vein was obstructed in 5 patients and unobstructed in the remaining 21 patients. In 23 patients, the vertical vein at its junction with the brachiocephalic vein was transected and was anastomosed to the left atrial append- 


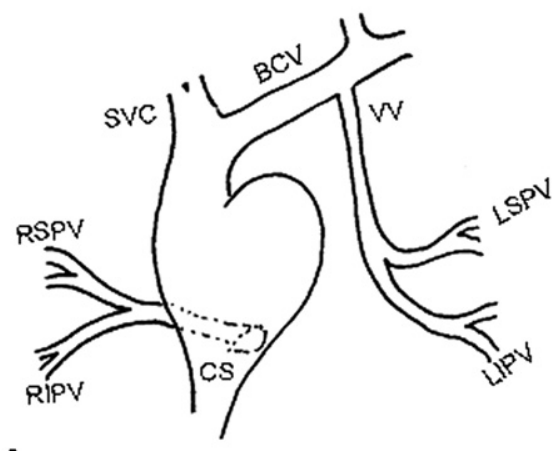

A

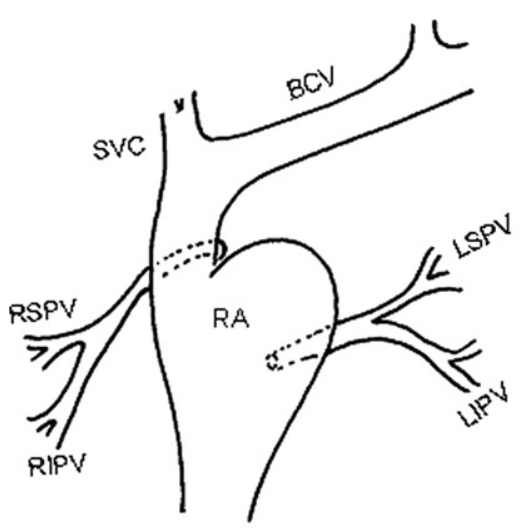

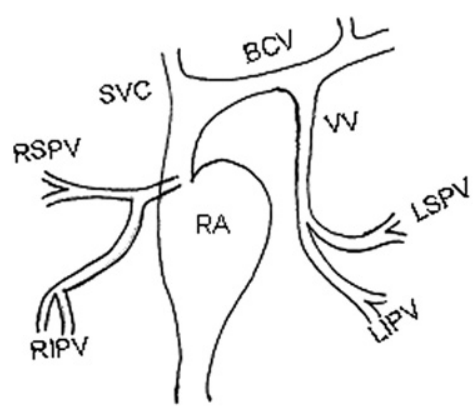

B

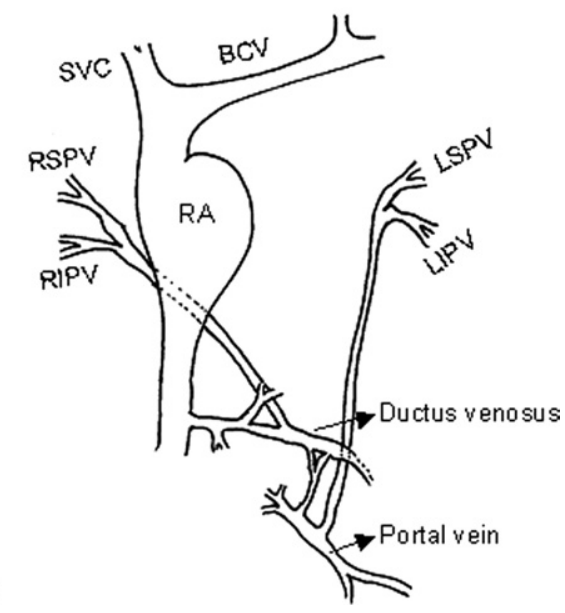

Figure 1. A to D, Group of patients with bilateral and symmetrical connections (" $2+2$ " pattern of drainage). BCV, Brachiocephalic vein; $C S$, coronary sinus; $L I P V$, left inferior pulmonary vein; LSPV, left superior pulmonary vein; $R A$, right atrium; $R I P V$, right inferior pulmonary vein; $\boldsymbol{R S P V}$, right superior pulmonary vein; $S V C$, superior vena cava; $V V$, vertical vein.

C

age, ensuring precise geometric alignment (avoiding tension, torsion, and rotation) and making as large an anastomosis as possible (Figure E1, $A$ to $D$ ). Three patients with an unobstructed isolated left superior pulmonary vein draining via the vertical vein into the brachiocephalic vein had been left with uncorrected anatomy. The remaining 3 patients with this variety of anomaly underwent rechanneling of the isolated pulmonary vein by individualized surgical techniques.

Category III: Patients with bizarre anatomic variants of mixed TAPVC. In our final group, we placed patients with pulmonary veins from both lungs draining in different combinations at different levels, but which did not permit categorization into any of the previous groups. We identified five different combinations of this type of mixed drainage in 5 described patients, accounting for $8.8 \%$ of the overall series. The anatomic variants were bizarre and required pulmonary venous rechanneling with individualized surgical techniques. The operative details of each morphologic subtype have been consolidated in Table 3 and Figure 3, $A$ to $E$.

In this series, we have used a Dacron patch to close the atrial septum, extending it to the right of the anastomosis of the pulmonary venous sinus in 12 patients. This serves to enhance the capacity of the left atrium but also ensures an adequate-sized communication between the pulmonary veins and left atrium. We maintained patency of the foramen ovale in patients with moderate-to-severe pulmonary hypertension for decompression of the right-sided chambers in the event of a pulmonary hypertensive crisis.

Left atrial pressure and PAP were monitored postoperatively in patients with moderate-to-severe pulmonary arterial hypertension. Postoperatively, patients were sedated and paralyzed during the first 24 to 48 hours. Pulmonary artery hypertension was treated with hyperventilation, sedation, phenoxybenzamine, sildenafil, and inhaled nitric oxide (10-15 ppm) as required.

All patients were routinely started on a regimen of dopamine (4 $\left.\mu \mathrm{g} \cdot \mathrm{kg}^{-1} \cdot \min ^{-1}\right)$ to increase renal perfusion and sodium nitroprusside $\left(0.5 \mu \mathrm{g} \cdot \mathrm{kg}^{-1} \cdot \mathrm{min}^{-1}\right)$ to reduce afterload and PAP. Patients considered to have low output syndrome $(n=19)$ required dopamine, dobutamine, epinephrine, and milrinone, either isolated or in combination.

The sternum was left open in $2(3.5 \%)$ patients. Delayed sternal closure was done 24 to 48 hours after hemodynamic stability had been obtained. Mean duration of ventilation was $3.08 \pm 4.1$ days (range, 1-24 days; median, 2 days). Twenty (35.1\%) patients received total parenteral nutrition commencing after 48 hours of ventilation. Postoperatively, digoxin, diuretics, and angiotensin-converting enzyme inhibitors were weaned at varying time intervals.

The mean CPB time was $81.24 \pm 18.22$ (range, 40-214 minutes; median, 80 minutes. Mean aortic crossclamp time was $52.80 \pm 11.58$ minutes (range, 24-82; median, 48 minutes). Left ventricular assist device or extracorporeal membrane oxygenation was not used in any patient in this study group. 


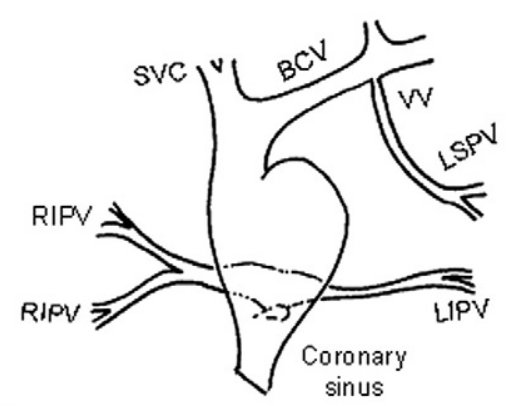

A

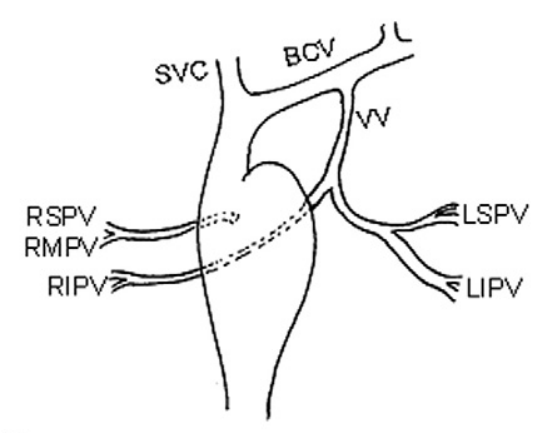

C

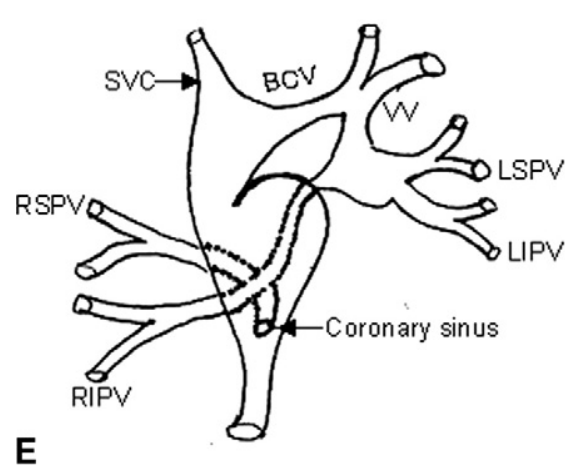

B

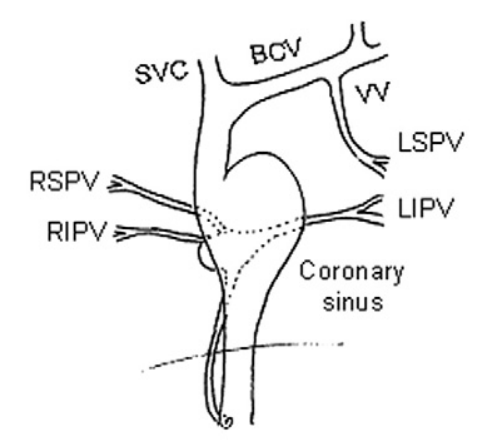

D
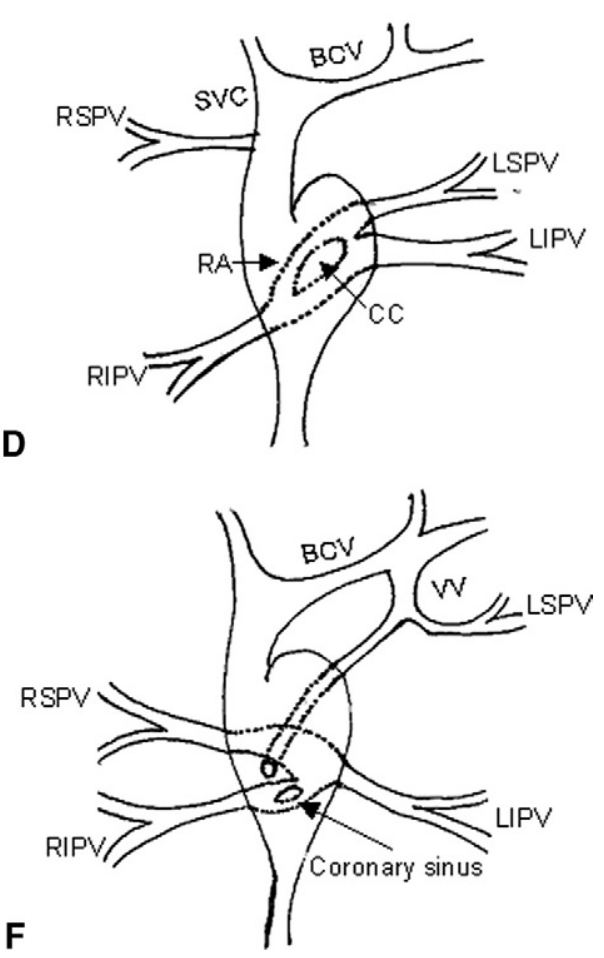

Figure 2. A to F, Group of patients with bilateral and asymmetrical connections (" $3+1$ " pattern of drainage). For abbreviations, see Figure 1.

\section{Statistical Methods and Analysis}

Statistical analysis was done with Intercooled STATA 9.0 Software (Stata Corporation, College Station, Tex). Continuous and interval-related data were expressed as the mean \pm standard deviation, whereas the categorical variables were expressed as frequency distribution and percentages. Quantitative data were analyzed with the Student $t$ test. Baseline predictors of mortality (related to cardiac disease and pulmonary hypertension) were identified by bivariate logistic regression analysis initially performed on candidate variables, including anatomic variations as a potential explanatory variable (Table E2). Multivariate logistic regression analysis was performed on the feasible independent variables (Table E3). Actuarial estimates were calculated with the Kaplan-Meier technique, and the log-rank test was performed to analyze the difference in survival between patients undergoing rechanneling of different varieties of mixed TAPVC.

\section{Results}

\section{Short-term Results}

There were $11(19.3 \%)$ early deaths resulting from persistent postoperative pulmonary artery hypertension and low cardiac output $(\mathrm{n}=9)$, massive pulmonary hemorrhage (n $=1)$, and septicemia $(\mathrm{n}=1)$. Thirty patients in this study had postoperative moderate pulmonary artery hypertension with stable hemodynamics. The systolic PAP in this subgroup of patients decreased to around half the systemic pressure intraoperatively. Subsequently, after the initial 24 hours, 16 patients had paroxysmal pulmonary hypertensive crises and were treated with hyperventilation, sedation, phenoxybenzamine, sildenafil, and inhaled nitric oxide (10-15 ppm) in varying combinations for 72 to 96 hours. Despite institution of the aforementioned measures, 9 patients died as a result of these hypertensive episodes. 

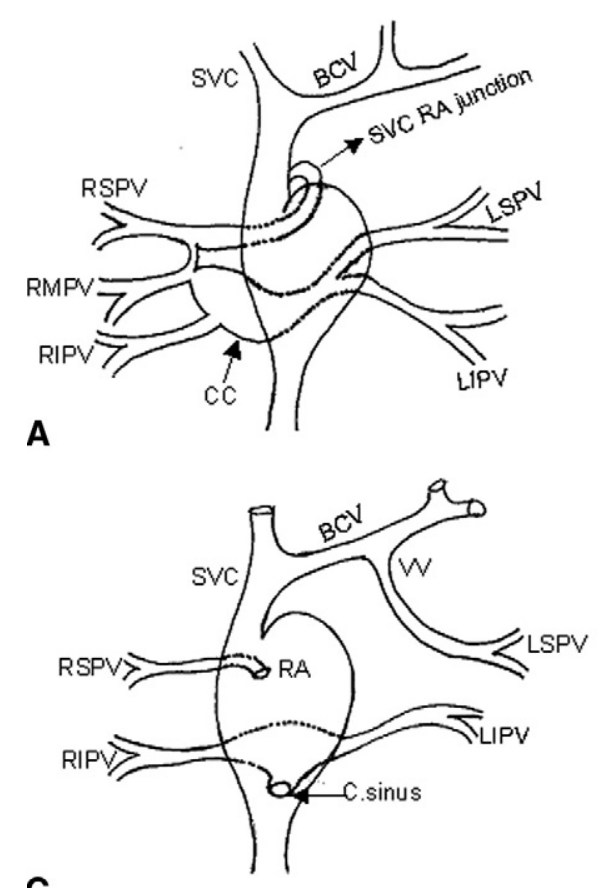

B

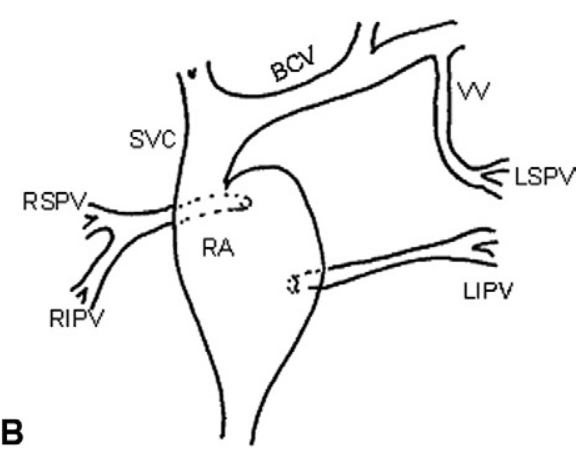

D

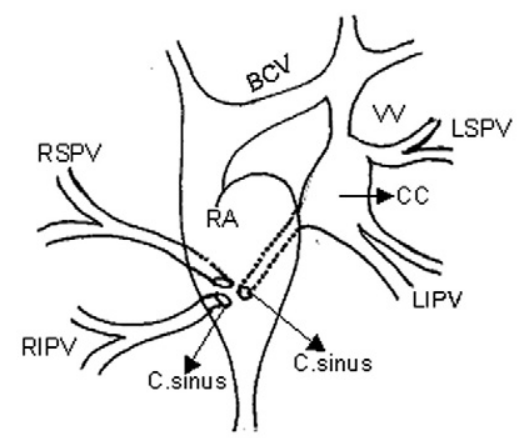

Figure 3. A to $E$, Group of patients of bizarre anatomic variants of mixed total anomalous pulmonary venous connection. CC, Common chamber; RCPV right common pulmonary vein; RMPV, right main pulmonary vein. For other abbreviations, see Figure 1.

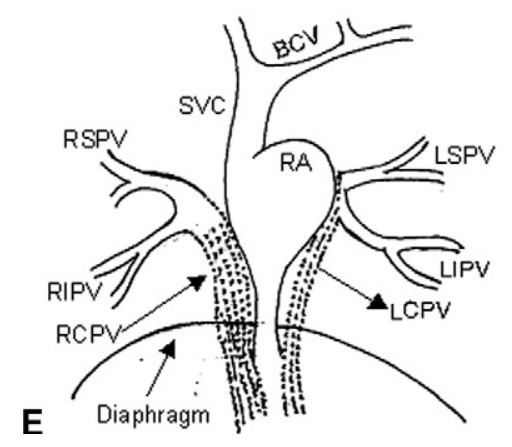

One $(1.7 \%)$ patient with retrocardiac plexus of pulmonary veins and diffusely small right- and left-sided pulmonary veins did not have a chamber sizeable enough for rechanneling. He died of severe pulmonary hemorrhage immediately after being weaned from bypass. Preoperatively, 2 patients exhibited small indexed pulmonary vein size and 1 patient had small pulmonary venous confluence size. Autopsy findings $(\mathrm{n}=3)$ documented bilateral small pulmonary venous confluences, diffuse hyperplasia, intimal hypertrophy, and increased medial thickness of the pulmonary arteries and veins with retrocardiac plexus of veins.

Five patients had postoperative infection. Despite a protracted course on ventilatory support and a tracheostomy, 1 patient died of septicemia.

Postoperative echocardiograms demonstrated a satisfactory primary repair (ie, a large anastomosis with no gradient between the pulmonary venous confluence and left atrium and nonturbulent biphasic pulmonary venous flow at less than $1.2 \mathrm{~m} / \mathrm{s}$ ). All patients undergoing vertical vein-brachiocephalic vein anastomosis $(n=23)$ demonstrated a patent, unrestricted anastomosis with nonturbulent biphasic pulmonary venous flow from the left upper pulmonary vein to the left atrial appendage (Figure E2). Serial echocardiograms during episodes of pulmonary hypertensive crises demonstrated right-to-left shunt through the patent foramen ovale in patients with atrial septal fenestration. CT angiography in a patient with mixed TAPVC 5 years postoperatively demonstrated a patent, unrestricted vertical vein-left atrial appendage anastomosis (Figure E3, $A$ and $B$ ).

Age less than 2 months, low body weight $(<50$ th percentile), presence of obstructive TAPVC, pulmonary hypertension, diffusely hypoplastic pulmonary veins, requirement of preoperative ventilation, inotropes, emergency operation, postoperative pulmonary hypertensive crises, low cardiac output, and category III of pulmonary venous drainage patterns were significant negative factors for survival according to bivariate logistic regression analysis (Table E2). 
Multvariate logistic regression analysis identified only four predictors for death after rechanneling of mixed TAPVC (Table E3). The risk of death was 5.85 times higher (95\% confidence interval $[\mathrm{CI}]: 1.46-35.68 ; P=.02$ ) in patients with category III of mixed TAPVC as compared with category I (" $2+2$ " pattern of mixed TAPVC).

\section{Late Outcomes}

There were 2 late deaths $4.3 \%$ ). One was due to recurrent pulmonary venous obstruction 2 months after surgery. This patient had the obstructed variety of mixed TAPVC preoperatively and died before any reintervention. The other patient died of sepsis $1 \frac{1 / 2}{2}$ year after TAPVC repair after reoperation for tracheal stenosis caused by tracheostomy. One patient was lost to follow-up.

Forty-three survivors have been followed up periodically every 6 months. Follow-up was 97.7\% complete (range, 1-192 months; mean $\pm \mathrm{SD}, 63.26 \pm 58.47$; median, 42 months) and yielded 150.5 patient-years of data with a mean survival time of 155 months ( \pm 10.0 ; 95\% CI: 136-175). The actuarial survival at $63.26 \pm 58.47$ months was $86.9 \%$ $\pm 0.07 \%, 86.2 \% \pm 0.06 \%$, and $20.0 \% \pm 0.18 \%$ in categories I, II, and III, respectively ( $P=.001)$ (Figure E4).

All survivors $(\mathrm{n}=43)$ had a Ross clinical heart failure score of 0 to 2 without any antifailure cardiac medications. At a mean follow-up of $63.26 \pm 58.47$ months, serial echocardiograms revealed normal biventricular function and absence of flow through the atrial septal fenestration.

\section{Discussion}

Mixed variety of TAPVC is a rare congenital entity eliciting clinical and surgical fascination. Analysis of the published literature demonstrates a wide spectrum of anatomic presentation and technical aspects of surgical repair. ${ }^{1-8,10-15}$

The correct preoperative diagnosis and an accurate anatomic description are essential for planning surgical treatment of these patients. ${ }^{1-8,10-15}$ No defined strategy for investigation of these patients has been addressed in the literature. The difficulties of diagnosis are inherently associated with the highly variable anatomy of mixed TAPVC.

Radiologic appearances of obstructive TAPVC with pulmonary hypertension are usually bilateral and symmetrical. ${ }^{1-7}$ In this study, 15 (26.3\%) patients showed asymmetric pulmonary venous congestion that signaled the possibility of the presence of more than one site of pulmonary venous connection or the hypoplastic state of one-sided pulmonary veins.

In most cases of TAPVC, echocardiography is sufficient for diagnosis and is preferable to cardiac catheterization. ${ }^{1-8}$ Some authors have stated that cardiac catheterization may be unnecessary if three veins are well visualized and there is no clinical evidence of obstruction. ${ }^{3}$ In this study, echocardiography was the only diagnostic study in 21 (36.8\%) patients. Cardiac catheterization was considered essential in $29(50.8 \%)$ patients for measuring PAP in late presenters, to delineate pulmonary venous anatomy in patients with suspected asymmetric pulmonary venous obstruction, to determine the etiology of systemic arterial desaturation, and to assess the presence of suspected major associated cardiac anomalies. In general, it is mandatory to identify all four pulmonary veins during the operation. Balloon atrial septostomy, once popular when repair was to be delayed, is now reserved for patients with complex anatomy requiring palliation. ${ }^{1-8,10-15}$ In this series, patients with restrictive ASD were taken to the operating room as soon as possible.

Magnetic resonance imaging, CT angiography, and transesophageal echocardiography with 3-dimensional analysis are other imaging modalities that may provide an accurate description of pulmonary venous drainage; early reports are promising, but clinical experience to date has been limited. ${ }^{16,17}$ In this study, CT angiography was required in 7 patients for further delineation of the pulmonary venous anatomy.

Because late presentation of congenital heart disease is not unusual in the developing world, it is not uncommon to be faced with adult patients with mixed TAPVC physiology. Twelve (21\%) patients undergoing surgery in this series were less than 2 months of age. The mean and median ages at repair were 18 months and 6 months, respectively. Only $1(1.7 \%)$ patient had a functionally univentricular heart with visceral heterotaxy and $1(1.7 \%)$ patient had recurrent pulmonary venous obstruction.

A large number of patients with mixed TAPVC and a functionally univentricular heart present in early infancy with ductus-dependent systemic/pulmonary blood flow and require urgent surgical intervention. ${ }^{1-6,18-20}$ The natural history is early death in the absence of surgical intervention. Most experts advise that these patients should have rechanneling of mixed TAPVC and a systemic-pulmonary shunt. ${ }^{1-6,18-20}$

Although our setting is a tertiary referral center, the socioeconomic profile of the patients and the lack of health insurance benefit led to delayed referral and surgery. The delayed referral pattern and thus early deaths of some of these patients would perhaps account for such late presentation. This was also probably the reason that only $1(1.7 \%)$ patient in this series had a functionally univentricular heart with visceral heterotaxy and 7 (12.2\%) patients had RA isomerism. This is in contrast to the published literature from the West, which documents the association of a functionally univentricular heart, RA isomerism, and asplenia in at least one third of patients with mixed TAPVC. ${ }^{1-6,18-20}$

Principles of management and surgical techniques of rechanneling of mixed TAPVC are difficult to define because of the small number of patients and incomplete ascertainment of the pulmonary venous anatomy in most 
individual surgical series. ${ }^{1-7,10-15}$ Because of the wide anatomic variations, various techniques and modifications have been published in the literature. ${ }^{1-7,10-15}$ Some of them require too many atrial incisions with the potential for atrial arrhythmias, and others do not offer adequate exposure. Additionally, these methods can be technically demanding and portend the risk of development of anastomotic stenosis, necessitating reoperations with a high mortality..$^{2-7,10-15}$

The surgical approaches to patients with mixed TAPVC have been individualized by classifying patients as having a " $2+2$ " connection or " $3+1$ " connection or any of the different connections enumerated in this series. In this study, the commonest pattern of mixed TAPVC was of " $3+1$ " variety, in which there was isolated drainage of solitary pulmonary veins with drainage of the other three veins to a common site. Although, rechanneling of the confluence of three pulmonary veins is easily performed when the drainage site is in the coronary sinus, vertical vein, or at the infradiaphragmatic level, the management of the remaining pulmonary vein needs to be individually tailored.

Rechanneling of the " $3+1$ " variety with drainage cephalad into the SVC risks the development of pulmonary venous obstruction and junctional arrhythmias. Several investigators have described ingenious techniques to eliminate those drawbacks. ${ }^{10,11,13,14}$

An obstructed isolated pulmonary vein mandates rechanneling into the left atrium, whereas an unobstructed isolated anomalous pulmonary venous drainage may be left uncorrected, can be corrected during a second operation if needed, or may require removal of the anomalously connected lobe. ${ }^{21}$ Although patients with uncorrected isolated pulmonary vein in this study $(n=3)$ have tolerated the operation with an excellent long-term outcome, there have been isolated reports of new-onset pulmonary vascular obstructive disease developing as a consequence of the leftto-right shunt present in patients with a single anomalous pulmonary vein. ${ }^{22,23}$

The following hypotheses have been proposed for its development: (1) possible pressure-sensitive receptors at the anomalous vein-vena cava junction, (2) an axon reflex triggered by RA distention, and (3) the result of increased flow in patients with an ASD. Therefore, close observation is needed in the follow-up of these patients. We concur with other investigators in advocating repair of all anomalously draining single pulmonary veins wherever feasible. ${ }^{24}$

The second common pulmonary venous drainage pattern was of " $2+2$ " variety, in which two pulmonary veins of each side joined a homolateral confluence and were connected with the systemic veins at separate sites. There was discontinuity of the right and left pulmonary venous drainage.

We have approached patients with a " $2+2$ " pattern of drainage as having bilateral partial anomalous pulmonary venous drainage. ${ }^{3}$ Several individualized techniques of rechanneling were used in this subset of patients $(n=23)$.

Concerns have arisen regarding patency of anastomosis to the left atrial appendage because this structure is heavily trabeculated. ${ }^{2}$ Although the literature does not specifically address the issue of long-term patency of this left-sided anastomosis, the excellent long-term outcome in patients with this anastomotic connection in this series as well as others suggests that clinically apparent obstruction is uncommon (Figures E2 and E3, $A$ and $B$ ).

In this study, we have encountered a rare case in which a separate vein from each lung joined a homolateral confluence. From each confluence, a vein descended into the abdomen to drain into the ductus venosus from the right lung and the portal vein from the left lung. Analysis of the published literature documents only 2 cases with two separate vertical veins draining below the diaphragm. ${ }^{7,12}$

The most outstanding feature of this study is the striking and persistent difference in surgical outcome of different groups of mixed TAPVC, despite minimization of invasive preoperative workup, evolution of new operative techniques, and aggressive uniform perioperative management protocol. Patients with mixed TAPVC with " $2+2$ " pattern of connections demonstrated superior outcomes after rechanneling compared with other patterns. Logistic regression analysis accounting for the effect of other factors demonstrated the following as significant predictors of perioperative deaths after rechanneling of mixed TAPVC: age less than 2 months, obstructive TAPVC, perioperative pulmonary hypertensive crises, and category III of mixed TAPVC. The risk of death was 5.85 times higher $(95 \% \mathrm{CI}$ : $1.46-35.68 ; P=.02)$ in patients with category III of mixed TAPVC (Table E3).

Another important finding of this investigation is the occurrence of suprasystemic PAP after coming off bypass given the age at operation. Despite modified surgical techniques aimed at increasing the dimension of the left atrial cavity, precise geometric alignment of the pulmonary venous chamber with the body of left atrium, avoiding torsion of the pulmonary veins, and introduction of phenoxybenzamine and nitric oxide, $9(15.8 \%)$ patients died postoperatively of recurrent pulmonary hypertensive crises. The important factors that have contributed to a high hospital mortality rate $(19.3 \%)$ in this study are late presentation, failure of early recognition, and thus delayed referral. This is in contrast to the West, where most patients $(>50 \%)$ were operated on before 1 month of age. ${ }^{1-4,6,18-20}$ In our earlier publication, we demonstrated that late referral and late presentation lead to the development of severe pulmonary hypertension, a prolonged period of malnutrition, and ultimately cardiac cachexia. These factors predispose the patients to pulmonary infection, sepsis, and postoperative 
pulmonary hemorrhage and they react unfavorably to stresses such as CPB and postoperative events. ${ }^{5}$

One patient with a retrocardiac plexus of pulmonary veins and diffusely hypoplastic right- and left-sided pulmonary veins did not have a chamber sizeable enough for rechanneling. The embryologic cause of this defect is uncertain, but this plexus may represent persistence of the splanchnic plexus that enmeshed the lung buds early in development. ${ }^{25}$

Anatomic studies by other investigators have shown that preoperative pulmonary venous obstruction is associated with increased medial thickness in both pulmonary arteries and veins, which exceeds by far the degree of changes observed in other lesions with pulmonary hypertension caused by left-to-right shunts alone. ${ }^{26}$ On the basis of these observations and from available evidence in the literature, we speculate that the medial and intimal changes seen in patients with preoperatively obstructive TAPVC may predispose to the development of intrinsic pulmonary vein stenosis and the outcome after surgery is poor, even in the presence of adequate pulmonary venous decompression. In light of the bleak prognosis for this subset of patients, alternative management strategies such as lung transplantation may perhaps be considered. ${ }^{27}$

The precise technique adopted in the individual patient must necessarily depend on the pattern of anomalous drainage, and an individualized management algorithm would be helpful, perhaps specified for each anatomic type.

\section{Study Limitations}

A limitation of this study is the low number of patients with a functionally univentricular heart and heterotaxy and also the limited number of patients with postoperative pulmonary venous stenosis. The population is clearly influenced by a natural selection as outlined in the text.

\section{Conclusions}

Mixed variety of TAPVC is a rare cardiac anomaly with a wide variation of pulmonary venous anatomy. The primary challenges posed by these patients centers around the diagnosis and technical aspects of surgical repair. There seems to be a limitation in diagnosis by echocardiography alone; cardiac catheterization and/or CT angiography in patients with stable hemodynamics are recommended if fewer then three pulmonary veins are identified by echocardiography. Careful intraoperative examination of the pulmonary venous drainage is mandatory for all patients. Surgical approaches vary according to whether a " $3+1$ " or " $2+2$ " or other complex pattern of pulmonary venous drainage is present. Pulmonary venous obstruction is relatively infrequent in this group of patients but, when present, affects patient survival significantly. Because of the morphologic heterogeneity, an individualized management algorithm is recommended.

\section{References}

1. Frieson CLH, Zurakowski D, Thiagrajan RR, Forbess JM, Nido PJD, Jonas RA. An analysis of current management strategies in a single institution. Ann Thorac Surg. 2005;79:596-606.

2. Ando M, Takahashi Y, Kikuchi T. Total anomalous pulmonary venous connection with dysmorphic pulmonary vein: a risk for postoperative pulmonary venous obstruction. Interact Cardiovasc Thorac Surg. 2004;3: 557-61

3. Delius RE, de Leval MR, Elliott WJ, Stark J. Mixed total pulmonary venous drainage: still a surgical challenge. J Thorac Cardiovasc Surg. 1996;112:1581-8.

4. Imoto Y, Kado H, Toshihide A, Shiokawa Y, Tominaga R, Yasui H. Mixed type of total anomalous pulmonary venous connection. Ann Thorac Surg. 1998;66:1394-7.

5. Choudhary SK, Bhan A, Sharma R, Airan B, Devagourou V, Saxena A, et al. Total anomalous pulmonary venous connection: surgical experience in Indians. Indian Heart J. 2001;53:754-60.

6. Delisle G, Ando M, Calder AL, Zuberbuhler JR, Rochenmacher S, Alday LE, et al. Total anomalous pulmonary venous connection: report of 93 autopsied cases with emphasis on diagnostic and surgical considerations. Am Heart J. 1976;91: 99-122.

7. Chowdhury UK, Malhotra A, Kothari SS, Reddy SK, Mishra AK, Pradeep KK, et al. A suggested new surgical classification for mixed totally anomalous pulmonary venous connection. Cardiol Young. 2007; 17:342-53.

8. Saxena A, Reddy SC, Kothari SS, Juneja R, Venugopal P, Shrivastava $\mathrm{S}$. Mixed variety of total anomalous pulmonary venous connection: diagnosis by $2 \mathrm{D}$ echocardiography and Doppler colour flow imaging. Indian Heart J. 1999;51:65-8.

9. Ross RD, Bollinger RO, Pinsky WW. Grading the severity of congestive heart failure in infants. Pediatr Cardiol. 1992;13:72-5.

10. Serraf A, Belli E, Roux D, Sousa-Uva M, Lacour-Gayet F, Planché C. Modified superior approach for repair of supracardiac and mixed total anomalous pulmonary venous drainage. Ann Thorac Surg. 1998;65: 1391-3.

11. Warden HE, Gustafson RA, Tarnay TJ, Neal WA. An alternative method for repair of partial anomalous pulmonary venous connection to the superior vena cava. Ann Thorac Surg. 1984;38:601-5.

12. Kanjuh VI, Katkob H, Singh A, Franciosi RA, Helseth HK, Edwards JE. Atypical total anomalous pulmonary venous connection: two channels leading to infracardiac terminations. Pediatr Cardiol. 1989;10:115-20.

13. Berdat PA, Pfammattr JP, Genyk I, Carrel TP. Modified repair of mixed total anomalous pulmonary venous connection. Ann Thorac Surg. 2001;71:723-5.

14. van Son JAM, Danielson GK, Puga FJ, Edwards WD, Driscoll DJ. Repair of congenital and acquired pulmonary vein stenosis. Ann Thorac Surg. 1995;60:144-50.

15. Chowdhury UK, Kothari SS, Airan B. Unusual totally anomalous pulmonary venous connection in right isomerism and functionally univentricular heart. Cardiol Young. 2001;11:75-8.

16. Choe YH, Lee HJ, Kim HS, Ko JK, Kim E, Han JJ. MRI of total anomalous pulmonary venous connections. J Comput Assist Tomogr. 1994;18:243-9.

17. Wang JK, Li YW, Chiu IS, Wu MH, Chang YC, Hung CR, et al. Usefulness of magnetic resonance imaging in the assessment of venoatrial connections, atrial morphology, bronchial situs and other anomalies in right atrial isomerism. Am J Cardiol. 1994;74:701-4.

18. Yun TJ, Al-Radi OO, Adatia I, Caldarone CA, Coles JG, Williams WG, et al. Contemporary management of right atrial isomerism: effect of evolving therapeutic strategies. J Thorac Cardiovasc Surg. 2006; 131:1108-13

19. Rubino M, Van Praagh S, Kadoba K, Pessotto R, Van Praagh R. Systemic and pulmonary venous connections in visceral heterotaxy with asplenia: diagnostic and surgical considerations based on seventytwo autopsied cases. J Thorac Cardiovasc Surg. 1995;110:641-50. 
20. Heinemann MK, Hanley FL, Van Praagh S, Fenton KN, Jonas RA, Mayer JE Jr, et al. Total anomalous pulmonary venous drainage in newborns with visceral heterotaxy. Ann Thorac Surg. 1994;57:8891.

21. Brantigan OC. Anomalies of the pulmonary veins. Their surgical significance. Surg Gynecol Obstet. 1947;84:653-8.

22. Babb JD, McGlynn TJ, Pierce WS, Kirkman PM. Isolated partial anomalous venous connection: a congenital defect with late and serious complications. Ann Thorac Surg. 1981;31:540-3.

23. Saalouke MG, Shapiro SR, Perry LW, Scott LP III. Isolated partial anomalous pulmonary venous drainage associated with pulmonary vascular obstructive disease. Am J Cardiol. 1977;39:439-44.
24. Van Meter C Jr, LeBlanc JG, Culpepper WS 3rd, Ochsner JL. Partial anomalous pulmonary venous return. Circulation. 1990;82(5 Suppl): IV195-8

25. Nakib A, Moller JH, Kanjuh VI, Edwards JE. Anomalies of pulmonary veins. Am J Cardiol. 1967;20:77-90.

26. Yamaki S, Tsunemoto M, Shiwada M, Ishizawa R, Endo M, Nakayama S, et al. Quantitative analysis of pulmonary vascular disease in total anomalous pulmonary venous connection in sixty infants. $J$ Thorac Cardiovasc Surg. 1992;104:728-35.

27. Mendeloff EN, Spray TL, Huddleston CB, Bridges ND, Canter CB, Mallory GB Jr. Lung transplantation for congenital pulmonary vein stenosis. Ann Thorac Surg. 1995;60:903-7.

Access to The Journal of Thoracic and Cardiovascular Surgery Online is reserved for print subscribers!

Full-text access to The Journal of Thoracic and Cardiovascular Surgery Online is available for all print subscribers. To activate your individual online subscription, please visit The Journal of Thoracic and Cardiovascular Surgery Online, point your browser to http://www.mosby.com/jtcvs, follow the prompts to activate your online access, and follow the instructions. To activate your account, you will need your subscriber account number, which you can find on your mailing label (note: the number of digits in your subscriber account number varies from 6 to 10 ). See the example below in which the subscriber account number has been circled:

\section{Sample mailing label}

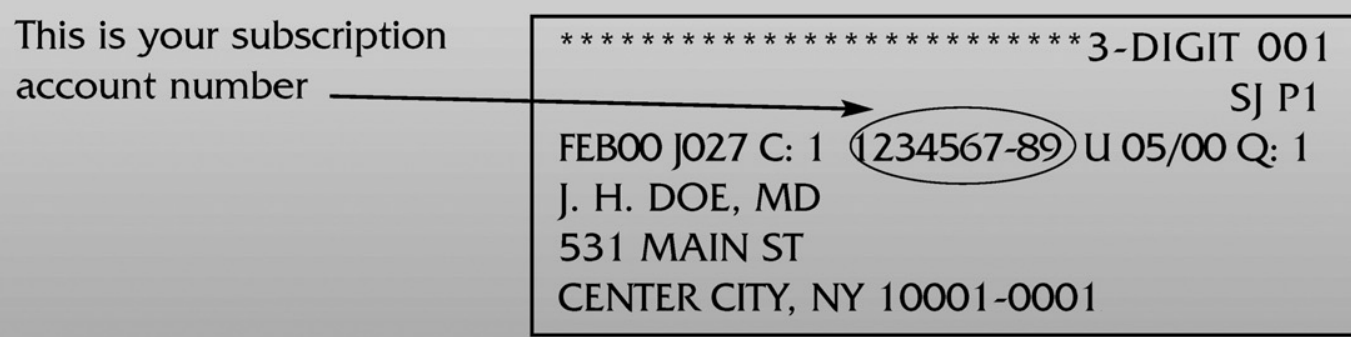

Personal subscriptions to The Journal of Thoracic and Cardiovascular Surgery Online are for individual use only and may not be transferred. Use of The Journal of Thoracic and Cardiovascular Surgery Online is subject to agreement to the terms and conditions as indicated online. 


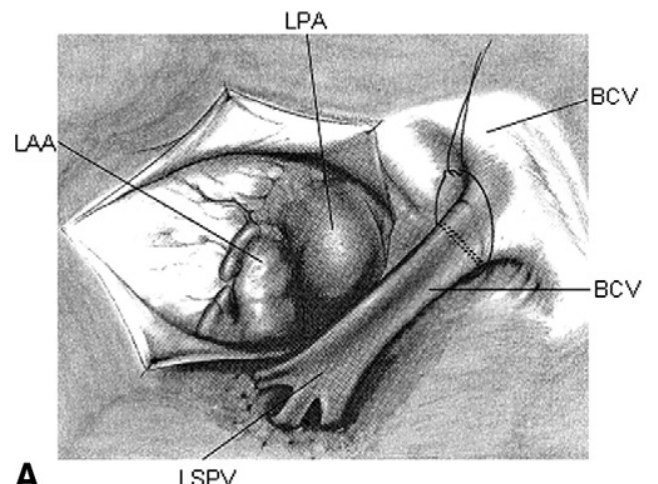

A

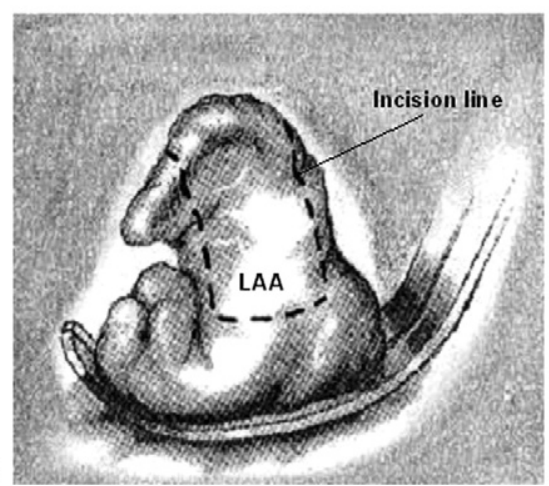

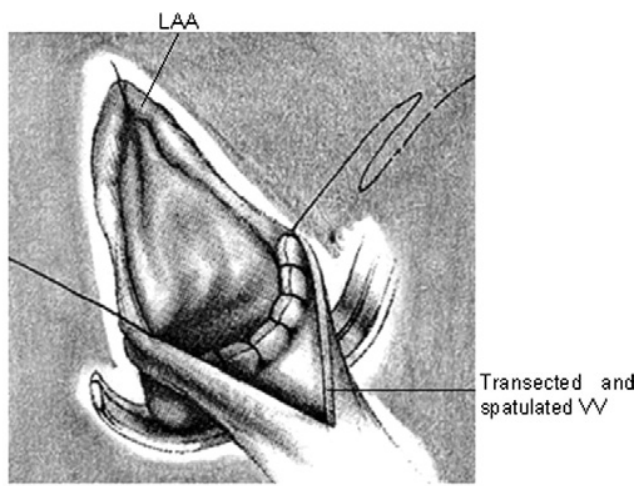

B

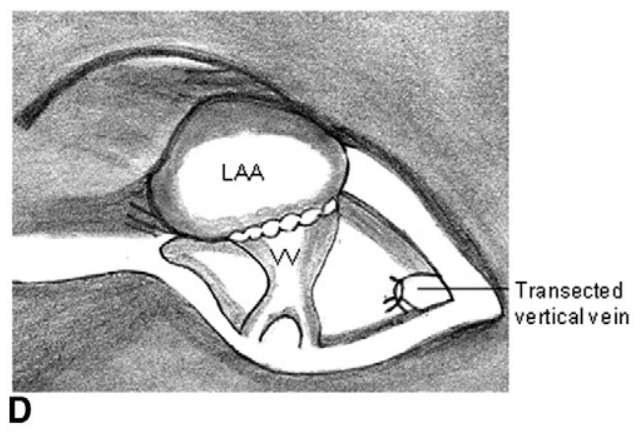

Figure E1. A to D, Diagrammatic representation of the steps of vertical vein-left atrial appendage anastomosis avoiding tension, torsion, and rotation. $B C V$, Brachiocephalic vein; $L A A$, left atrial appendage; $L P A$, left pulmonary artery; $L S P V$, left superior pulmonary vein; $V V$, vertical vein.

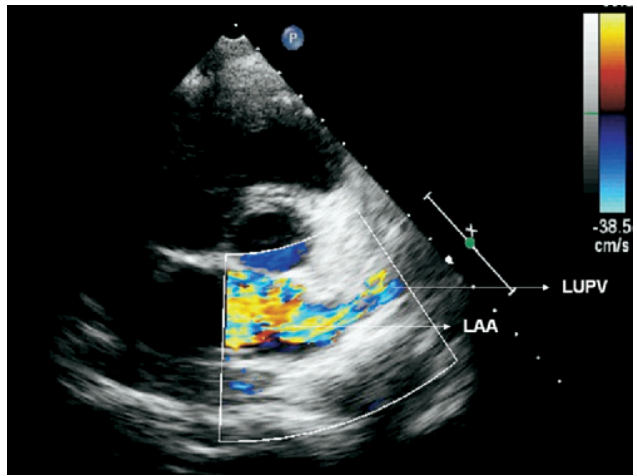

Figure E2. Two-dimensional and Doppler echocardiogram of a patient with mixed total anomalous pulmonary venous connection showing left upper pulmonary vein (LUPV) entering the left atrial appendage (LAA) with nonturbulent, biphasic pulmonary venous flow from the LUPV to the LAA. 

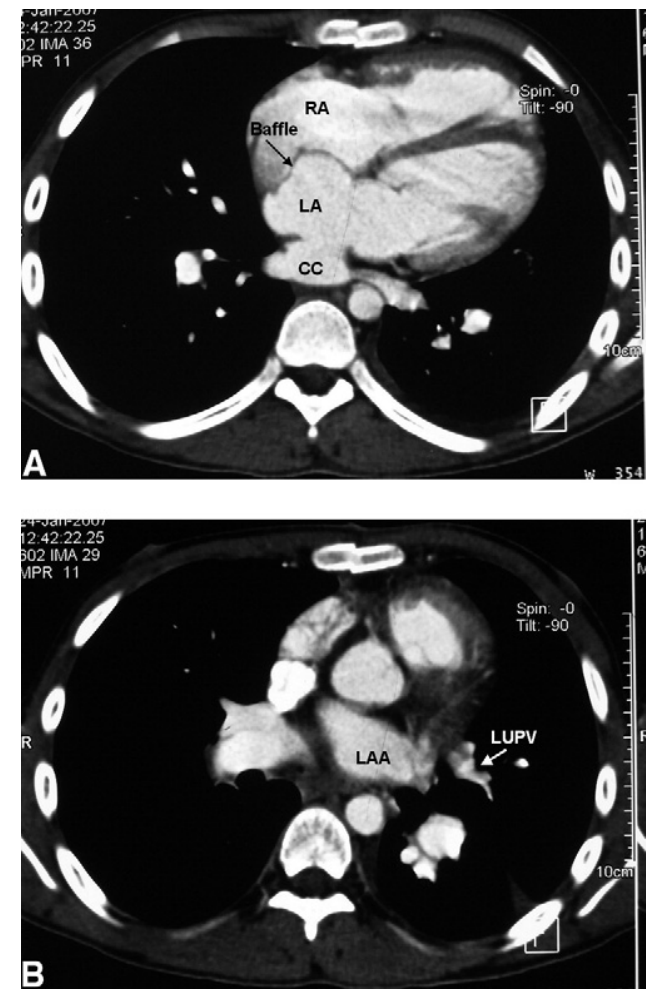

Figure E3. A and B, Computed tomographic angiogram of a patient with mixed total anomalous pulmonary venous connection 5 years postoperatively showing a patent, unrestricted vertical vein-left atrial appendage (LAA) anastomosis. This figure also shows a polytetrafluoroethylene baffle between the left atrium (LA) and right atrium (RA). CC, Common chamber; LUPV, left upper pulmonary vein.

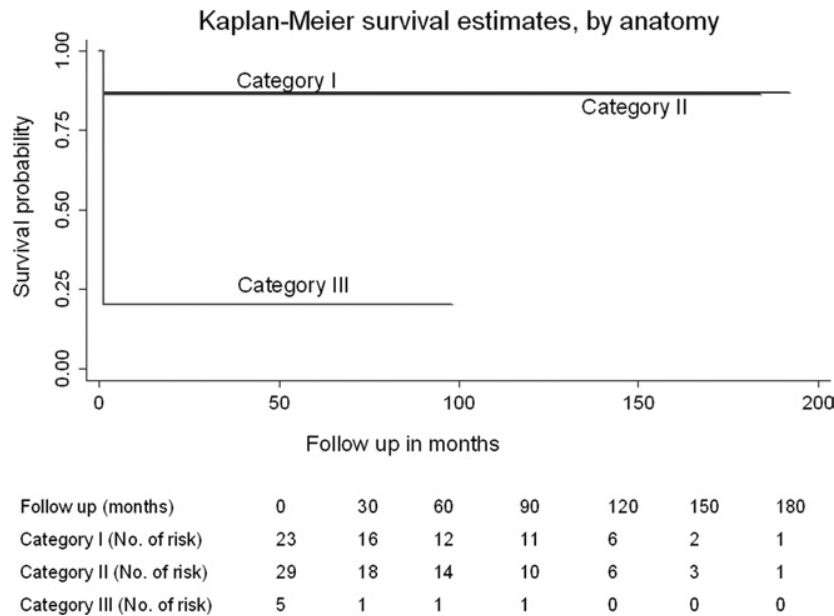

Figure E4. Actuarial survival curve (Kaplan-Meier) of three categories of patients with mixed total anomalous pulmonary venous connection undergoing rechanneling of the same in the study group. 
TABLE E1. Demographic, operative, and postoperative details of the study group

\begin{tabular}{|c|c|}
\hline Patient-related variables & Mean \pm SD (range) \\
\hline No. of patients & 57 \\
\hline Age at operation (mo) & $18.40 \pm 40.12(15 \mathrm{~d}-18 \mathrm{y} ;$ median $6 \mathrm{mo})$ \\
\hline Weight at operation $(\mathrm{kg})$ & $5.12 \pm 5.85(2.5-46$ kg; median 5 kg) \\
\hline \multicolumn{2}{|l|}{ Sex } \\
\hline Male & $36(63.1 \%)$ \\
\hline Female & $21(36.8 \%)$ \\
\hline \multicolumn{2}{|l|}{ Obstruction (one/more pulmonary veins) } \\
\hline Yes & $19(33.3 \%)$ \\
\hline No & $38(66.7 \%)$ \\
\hline \multicolumn{2}{|l|}{ Anatomy } \\
\hline “2+2" pattern & $23(40.3 \%)$ \\
\hline “3+1" pattern & $29(50.9 \%)$ \\
\hline Other patterns & $5(8.8 \%)$ \\
\hline \multicolumn{2}{|l|}{ Preoperative hemodynamic data (catheterized, $\mathrm{n}=29$ ) } \\
\hline \multicolumn{2}{|l|}{ Systolic PAP } \\
\hline$<18 \mathrm{~mm} \mathrm{Hg}$ & 0 \\
\hline$>18 \mathrm{~mm} \mathrm{Hg}$ & 29 \\
\hline Mean PAP in patients with systolic PAP (>18 mm Hg, $\mathrm{n}=28$ ) & $58.80 \pm 12.52(38-83)$ \\
\hline \multicolumn{2}{|l|}{ RVSP/LVSP } \\
\hline $1.2 \pm 0.2$ & $4(7.0 \%)$ \\
\hline $0.7 \pm 0.2$ & $53(93 \%)$ \\
\hline Preoperative $\mathrm{SaO}_{2}$ & $75 \pm 4(70 \%-94 \%)$ \\
\hline \multicolumn{2}{|l|}{ Preoperative mechanical ventilation } \\
\hline Yes & $4(7.0 \%)$ \\
\hline No & $53(93 \%)$ \\
\hline \multicolumn{2}{|l|}{ Preoperative inotropes } \\
\hline Yes & $4(7.0 \%)$ \\
\hline No & $53(93 \%)$ \\
\hline \multicolumn{2}{|l|}{ Operation timing } \\
\hline Emergency & $4(7.0 \%)$ \\
\hline Elective & $53(93 \%)$ \\
\hline \multicolumn{2}{|l|}{ Mortality } \\
\hline Overall & $13(22.8 \%)$ \\
\hline Cardiac and pulmonary hypertension related & $11(19.3 \%)$ \\
\hline \multicolumn{2}{|l|}{ Pulmonary hypertensive crisis } \\
\hline Yes & $16(28.1 \%)$ \\
\hline No & $41(71.9 \%)$ \\
\hline \multicolumn{2}{|l|}{ Low cardiac output } \\
\hline Yes & $19(33.3 \%)$ \\
\hline No & $38(66.7 \%)$ \\
\hline Duration of mechanical ventilation & $3.04 \pm 3.82(1--22 \mathrm{~d} ;$ median $2 \mathrm{~d})$ \\
\hline ICU stay & $6.1 \pm 4.8(1-30 \mathrm{~d} ;$ median $8 \mathrm{~d})$ \\
\hline Hospital stay & $10.42 \pm 6.2(1-42 \mathrm{~d} ;$ median $12 \mathrm{~d})$ \\
\hline
\end{tabular}


TABLE E2. Predictors of 0-to-16 years' mortality (cardiac and pulmonary hypertension related) by bivariate logistic regression analysis applied to all 57 patients

\begin{tabular}{|c|c|c|c|c|}
\hline Variables & No. & Death & Odds ratio $95 \% \mathrm{Cl}$ & $P$ value \\
\hline \multicolumn{5}{|l|}{ Age } \\
\hline$<2$ mo & 12 & 5 & $4.64(1.11-19.48)$ & .04 \\
\hline$>2 \mathrm{mo}$ & 45 & 6 & & \\
\hline \multicolumn{5}{|l|}{ Sex } \\
\hline Male & 36 & 7 & $1.03(0.22-4.97)$ & .999 \\
\hline Female & 21 & 4 & & \\
\hline \multicolumn{5}{|l|}{ Body weight } \\
\hline$<50$ th percentile & 25 & 8 & $4.55(1.06-19.50)$ & .03 \\
\hline$>$ 50th percentile & 32 & 3 & & \\
\hline \multicolumn{5}{|l|}{ Obstruction } \\
\hline Yes & 19 & 9 & $16.20(3.0-87.34)$ & $<.001$ \\
\hline No & 38 & 2 & & \\
\hline \multicolumn{5}{|l|}{ Mean PAP } \\
\hline$>18 \mathrm{~mm} \mathrm{Hg}$ & 28 & 10 & $15.56(1.83-32.11)$ & .002 \\
\hline$<18 \mathrm{~mm} \mathrm{Hg}$ & 29 & 1 & & \\
\hline \multicolumn{5}{|c|}{ Preoperative RVSP/LVSP } \\
\hline $1.2 \pm 0.2$ & 3 & 2 & $10.0(0.8-122.4)$ & .09 \\
\hline $0.7 \pm 0.2$ & 54 & 9 & & \\
\hline \multicolumn{5}{|c|}{ Preoperative ventilation } \\
\hline Yes & 4 & 3 & $16.87(1.56-183.22)$ & .02 \\
\hline No & 53 & 8 & & \\
\hline \multicolumn{5}{|c|}{ Preoperative inotropes } \\
\hline Yes & 4 & 3 & $16.87(1.56-183.22)$ & .02 \\
\hline No & 53 & 8 & & \\
\hline \multicolumn{5}{|l|}{ Timing } \\
\hline Emergency & 4 & 3 & $16.87(1.56-183.22)$ & .02 \\
\hline Elective & 53 & 8 & & \\
\hline \multicolumn{5}{|l|}{ Low cardiac output } \\
\hline Yes & 19 & 10 & $41.1(4.64-364.0)$ & $<.001$ \\
\hline No & 38 & 1 & & \\
\hline \multicolumn{5}{|c|}{ Pulmonary hypertensive crisis } \\
\hline Yes & 16 & 9 & $25.1(4.4-141.5)$ & $<.001$ \\
\hline No & 41 & 2 & & \\
\hline \multicolumn{5}{|c|}{$\begin{array}{l}\text { Diffusely hypoplastic pulmonary veins, small pulmonary } \\
\text { venous confluence, retrocardiac venous plexus }\end{array}$} \\
\hline Yes & 4 & 3 & $16.87(1.56-183.22)$ & .02 \\
\hline No & 53 & 8 & & \\
\hline \multicolumn{5}{|l|}{ Anatomy } \\
\hline " $2+2$ " pattern & 23 & 3 & - & - \\
\hline “3+1” pattern & 29 & 4 & $1.07(0.21-5.33)$ & .94 \\
\hline Other patterns & 5 & 4 & $26.7(2.18-326.45)$ & .01 \\
\hline
\end{tabular}

$\mathrm{Cl}$, Confidence interval; $P A P$, pulmonary artery pressure; RVSP/LVSP, right ventricular/left ventricular systolic pressure ratio. Boldface indicates statistical significance. 
TABLE E3. Predictors of 0-to-16 years' mortality (cardiac and pulmonary hypertension related) by stepwise logistic regression analysis applied to all $\mathbf{5 7}$ patients

\begin{tabular}{lrc}
\hline Step 4a: Variables (covariates adjusted) & Odds ratio (95\% CI) & $\boldsymbol{P}$ value \\
\hline Age $\leq 2$ mo & $5.18(1.23-21.82)$ & .02 \\
Obstructive TAPVC & $12.70(2.46-74.68)$ & $\mathbf{. 0 1}$ \\
Pulmonary hypertensive crises & $10.28(1.46-56.75)$ & .02 \\
Cardiac anatomy (category III) & $5.85(1.46-35.68)$ & $\mathbf{. 0 2}$ \\
\hline
\end{tabular}

$\overline{C l \text {, Confidence interval; TAPVC, total anomalous pulmonary venous con- }}$ nection. Boldface indicates statistical significance. 